1 Schou M, Amdisen A, Jensen SE, Olsen T. Occurrence of goitre during lithium treatment. $B M F$ 1968;iii:710-3.

2 Brownlie BEW, Chambers ST, Sandler WA, Donald RA. Lithium associated thyroid disease - a report of 14 cases Lithium associated thyroid disease - a report of 14 cases
of hypothyroidism and 4 cases of thyrotoxicosis. Aust NZ

3 Lindstedt G, Nilsson LA, Walinder J, Skott A, Ohman R. On the prevalence, diagnosis and management of lithiuminduced hypothyroidism in psychiatric patients. $B r f P s y-$ chiatry 1977;130:452-8.

4 Rosser R. Thyrotoxicosis and lithium. Br f Psychiatry 1976; 128:61-6.

5 Franklin LM. Thyrotoxicosis developing during lithium treatment: case report. NZ Med f 1974;79:782.

6 Reus VI, Gold P, Post R. Lithium-induced thyrotoxicosis. Am $\mathcal{f}$ Psychiatry 1979;136:724-5.

7 Kontozoglou T Mambo N. The histopathologic features of lithium-associated thyroiditis. Hum Pathol 1983;14:737-9.
8 Fauerholdt L, Vendsborg P. Thyroid gland morphology after lithium treatment. Acta Pathol Microbiol Scand Sect A 1981; 89:339-41.

9 Berens SC, Bernstein RS, Robbins J, Wolff J. Antithyroid effects of lithium. $₹$ Clin Invest 1970;49:1357-67.

10 Mizukami Y, Michigishi T, Nonomura A, et al. Postpartum thyroiditis - a clinical, histologic and immunopathological thyroiditis - a clinical, histologic and immunopathological

11 Smyrk TC, Goellner JR, Brennan MD, Carney JA. Pathology of the thyroid in amiodarone-associated thyrotoxicosis. Am $₹$ Surg Pathol 1987;11:197-204.

12 Carney JA, Moore SB, Nothcatt RC, Woolner LB, Stillwel GK. Palpation thyroiditis (multifocal granulomatous folliculitis). Am ₹ Clin Pathol 1975;64:639-47.

13 Mizukami Y, Michigishi T, Nonomura A, Nakamura S, Ishizaki $T$. Pathology of chronic thyroiditis: A new clinically relevant classification. Pathol Annu 1994;29: 135-58.

\title{
Splenic lymphoma with circulating villous lymphocytes
}

\author{
F Imbing Jr, D Kumar, S Kumar, G Yuoh, F Gardner
}

\begin{abstract}
This report describes the occurrence of splenic lymphoma with villous lymphocytes (SLVL) in a 56 year old white female with a family history of chronic lymphocytic leukaemia. Other unusual features included a marked lymphocytosis with counts up to $224 \times 10^{9} / 1$ and marked clumping of lymphocytes in EDTA anticoagulated blood. The neoplastic cells were $\mathrm{CD} 19+, \mathrm{CD20}+, \mathbf{C D 2 2}+, \mathrm{CD} 22+$, $\operatorname{IgM}+, \lambda+, \kappa-, \operatorname{CD5}-$, and CD10-. The spleen had nodular infiltrates of $B$ lymphocytes in the region of the white pulp with minimal red pulp involvement. Electron microscopy of peripheral blood lymphocytes revealed cells with polar cytoplasmic processes. This report underlines the need for detailed analysis, including morphology and immunophenotyping, for each patient with a small B cell lymphoproliferative disorder

( $f$ Clin Pathol 1995;48:584-587)
\end{abstract}

Pathology, The University of Texas Medical Branch, Texas, USA F Imbing Jr

D Kumar

$S$ Kumar

G Yuoh

Department of Internal Medicine F Gardner

Correspondence to: Dr D Kumar, Department of Pathology, Division of Anatomical Pathology, 22 South Greene Street, Baltimore MD 21201-1595, USA.

Accepted for publication 13 October 1994
Keywords: Splenic lymphoma with villous lymphocytes, immunophenotype, familial, electron microscopy.

The disease now referred to as splenic lymphoma with villous lymphocytes (SLVL) ${ }^{1}$ was previously described by Neiman et $a l^{2}$ under the rubric malignant lymphoma simulating leukaemic reticuloendotheliosis. In their study of 10 cases, Neiman et al compared and contrasted this disorder with hairy cell leukaemia (HCL) and prolymphocytic leukaemia (PLL) and emphasised the importance of a histological examination of the spleen in making the distinction. The patient described here was ini- tially thought to have B chronic lymphocytic leukaemia (CLL) based on her family history. A diagnosis of SLVL was later made by correlating the morphology and immunophenotype of peripheral blood lymphocytes and histology of the resected spleen.

\section{Case report}

A 56 year old white female presented with progressively increasing abdominal girth in November 1993. On physical examination, the spleen was massively enlarged, being palpable $13 \mathrm{~cm}$ below the left costal margin. There was no peripheral lymphadenopathy. Abdominal computed tomography scans confirmed massive splenomegaly with hypodense areas suggestive of leukaemic or lymphomatous infiltrate, or both. No mediastinal or abdominal lymphadenopathy was observed.

Examination of the peripheral blood revealed a haemoglobin concentration of $104 \mathrm{~g} / 1$; a platelet count of $121 \times 10^{9} / 1$; a white blood cell count (WBC) of $69 \times 10^{9} / 1$, with $98 \%$ lymphocytes. The lymphocytes were larger than small lymphocytes and had a moderate amount of cytoplasm. The nuclei were round, with few clefted and irregular forms and had a clumped chromatin pattern (fig 1). Small but distinct nucleoli were present in some of the cells. Irregularly distributed surface projections, which were sometimes concentrated at one or both poles of the cell, were seen in some cells. An unusual feature noticed in the smears was marked clumping of the lymphocytes (fig 1). The leukaemic cells were tartrate resistant acid phosphatase (TRAP) negative. Electron microscopic studies were carried out on buffy coated preparations of peripheral blood. Small villous 


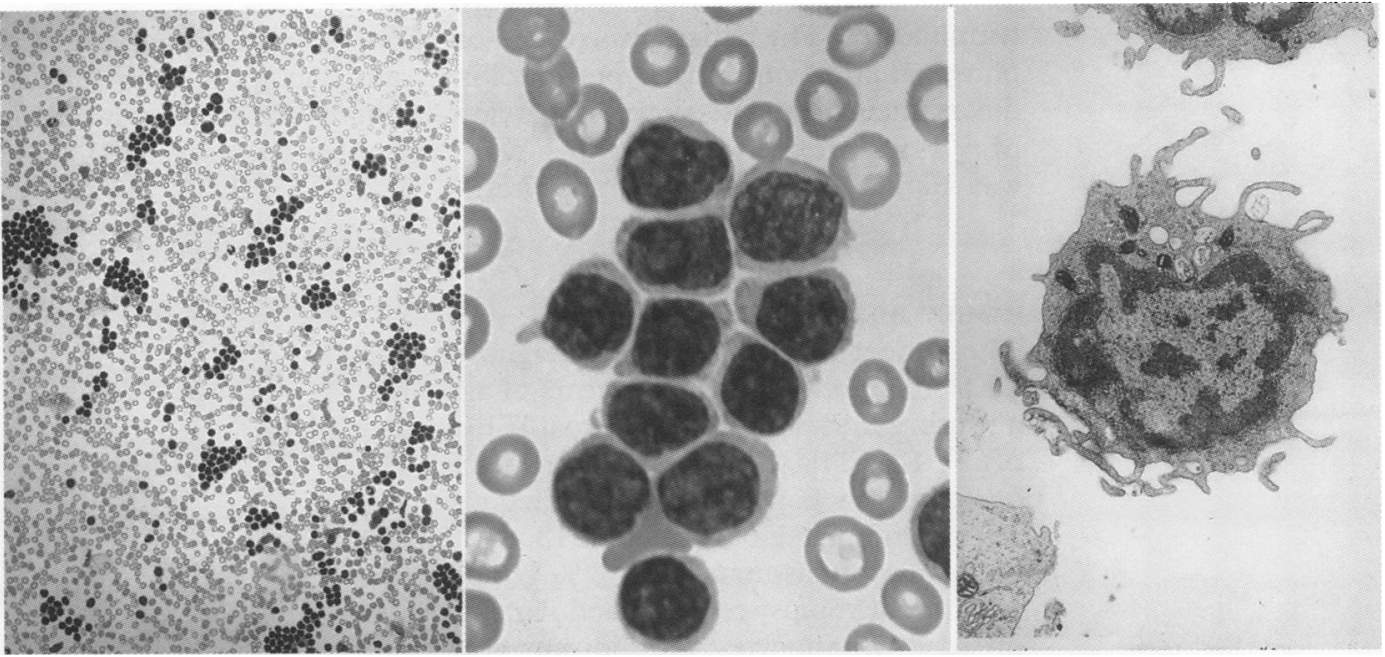

Figure 1 The panel on the left shows clumping of lymphoma cells in the peripheral blood smear $(\times 250)$. At high magnification (middle panel; $\times 1000)$, the neoplastic cells have a moderate amount of cytoplasm and a round to irregular nucleus with clumped chromatin. The electron micrograph shows the polar distribution of the villous processes (right panel; $\times 9000$ ).

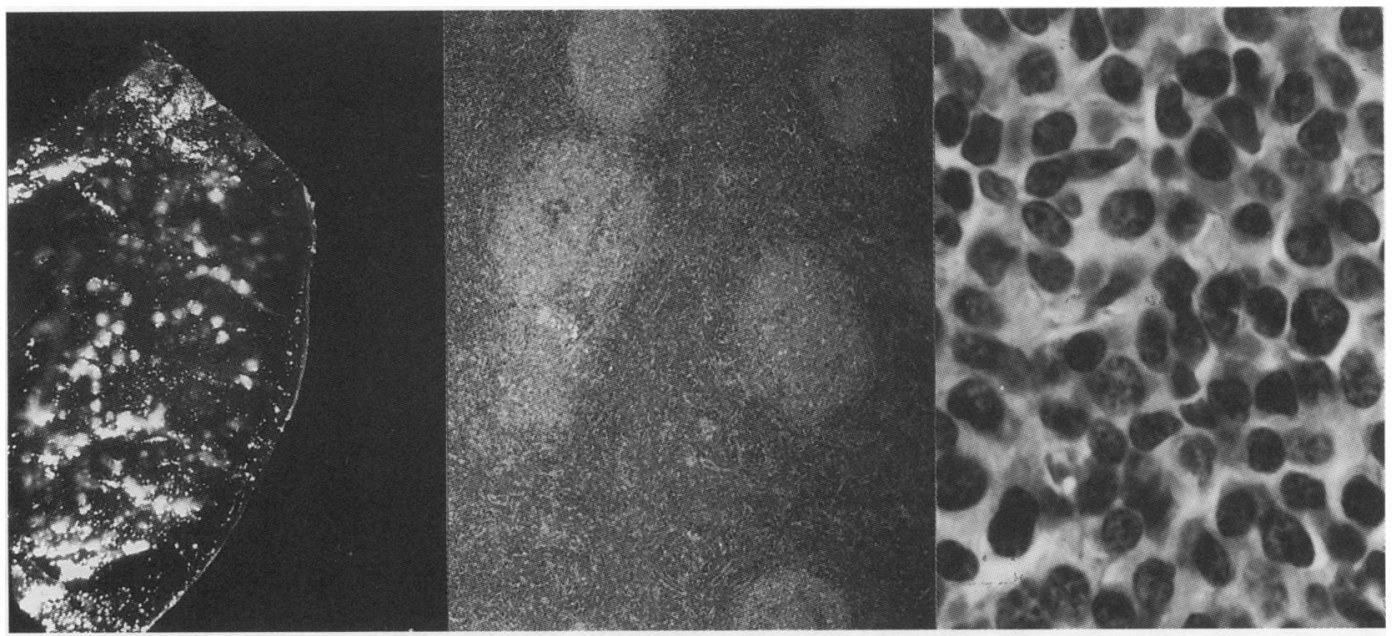

Figure 2 A portion of the spleen showing nodular involvement of the white pulp (left panel). At low magnification, exclusive involvement of the white pulp with effacement of its architecture can be seen (middle panel; $\times 100$ ). At high magnification, the lymphoma cells have round to slightly irregular nuclei, moderately clumped chromatin and inconspicuous nucleoli (right panel; $\times 400$ ).

cytoplasmic projections were seen arranged at one or both poles of many of the neoplastic cells (fig 1).

Flow cytometric immunophenotyping of gated lymphocytes gave the following results: CD $45+$, 98\%; HLA-DR +, 95\%; CD10+, 91\%; CD20 +, 94\%; CD22 +, 93\%; CD10 +, $0 \% ; \operatorname{IgM}+; 93 \%$; IgG +, $1 \% ; \lambda+, 92 \% ; \kappa+$, $0 \%$; $\mathrm{CD} 1+0 \%$; CD2 +, 7\%; CD3 +, 5\%; $\mathrm{CD} 4+, 3 \%$; CD $5+, 9 \%$; $\mathrm{CD} 7+, 5 \%$; CD $8+$, 2\%; CD11c+, 3\%; CD13+, 3\%; CD14+, $1 \%$; CD 15 + , 4\%; CD33 + , $1 \%$; and CD34 +, $1 \%$. A diagnosis of a $\mathrm{B}$ cell lymphoproliferative disorder with $\operatorname{IgM}, \lambda$ light chain restriction was made. It was noted that the neoplastic cells lacked CD11c, CD10 and CD5 antigens.

Serum protein electrophoresis showed normal levels of IgG, IgA, and IgM. No $M$ spike was present. Direct and indirect antiglobulin tests were negative.

The patient was started on chlorambucil, prednisilone and allopurinol. Her WBC counts varied between $163-224 \times 10^{9} / 1$ with $95-99 \%$ lymphocytes. The patient became severely anaemic (haemoglobin concentration, $59 \mathrm{~g} / \mathrm{l}$ ) and thrombocytopenic (platelets, $43 \times 10^{9} / 1$ ). As the spleen continued to increase in size, a course of radiation was given without any response. Splenectomy was performed in February 1994.

The spleen was $2010 \mathrm{~g}$ in weight. Serial sections revealed multiple white nodules up to $0.3 \mathrm{~cm}$ in diameter, involving the whole spleen (fig 2). On histological examination, there was effacement of the while pulp by nodular aggregates of neoplastic lymphoid cells which coalesced in some areas. There was minimal involvement of the red pulp. The neoplastic lymphocytes were small to medium in size, with scanty cytoplasm and had round to slightly irregular nuclei containing moderatively coarse chromatin. Nucleoli were inconspicuous (fig 2 ). The mitotic count was three per high power field $(\times 400)$. The neoplastic cells did not show a marginal or a mantle zone pattern of arrangement. These cells stained positively for the CD20 antigen using the L-26 antibody. No staining was observed with the Leu-22 antibody.

Post-operative WBC counts fluctuated between $72 \times 10^{9}$ and $161 \times 10^{9} / 1$ with $84-90 \%$ 
lymphocytes. The patient was placed on cyclophosphamide, vincristine, prednisolone, and doxorubicin therapy. At the last follow-up in May 1994, after two courses, her WBC count was $46 \times 10^{9} / 1$ with $95 \%$ lymphocytes.

\section{FAMILY HISTORY}

The patient's father had been diagnosed with CLL in October 1984 at 71 years of age when a routine work up revealed a total WBC count of $21.1 \times 10^{9} / 1$ with $81 \%$ lymphocytes. His haemoglobin concentration at diagnosis was $151 \mathrm{~g} / 1$ and platelet count was $213 \times 10^{9} / 1$. The bone marrow aspirate had $67 \%$ lymphocytes and the core biopsy revealed nodular aggregates of small lymphocytes. He did not receive any therapy for CLL before his death in May 1986 from an unrelated cause.

Information on the patient's brother was obtained from the necropsy report. He had been diagnosed with CLL in 1988 at the age of 45 years. The total leucocyte count in July 1990 was $94 \times 10^{9} / 1$ with $95 \%$ lymphocytes. The morphology of the leukaemic cells was described to be typical of CLL. Additionally, immunophenotypic studies carried out using flow cytometry revealed the following phenotype: HLA-DR+, $91 \% ; \kappa+, 91 \%$; CD5, $100 \% ; \lambda+, 9 \%$; and CD2,$+ 6 \%$. The patient underwent multiple courses of chemotherapy to which he was refractory. At his last admission in February 1993 he was leucopenic (WBC count $\left.2.2 \times 10^{9} / 1\right)$ and thrombocytopenic (platelet count $\left.15 \times 10^{9} / 1\right)$. Almost all of the leucocytes in the peripheral blood were large abnormal lymphocytes. He died soon thereafter of disseminated Aspergillus and Pseudomonas infections. Pertinent findings at necropsy were splenomegaly (weight $2000 \mathrm{~g}$ ) with no mass lesions, and mediastinal and para-aortic lymphadenopathy. Leukaemic infiltrates were present in bone marrow, spleen and lymph nodes. The neoplastic cells were described as large and atypical.

\section{Discussion}

SLVL is a B cell lymphoproliferative disorder that usually presents with marked splenomegaly and moderate lymphocytosis. ${ }^{13}$ As CLL, PLL, HCL, and the leukaemic phases of mantle cell lymphoma (MCL) and small cleaved cell lymphoma (SCCL) can have similar clinicopathological features, a diagnosis of this disorder can only be made following detailed immunophenotypic and morphological, including electron microscopy, studies. B-CLL is the most common of the familial leukaemias ${ }^{4}$ and therefore CLL was the first diagnostic consideration in our patient. The degree of peripheral lymphocytosis observed was also in keeping with this diagnosis, as in SLVL lymphocytosis is usually not very high. In a study of a large group of patients with SLVL the highest absolute lymphocyte count observed was $35 \times 10^{9} / 1^{1}$ The lymphocytes in CLL, however, are small with a high nuclear to cytoplasmic ratio and clumped nuclear chromatin. Im- munophenotypically, B-CLL cells are CD5+ in more than $90 \%$ of cases. ${ }^{5}$ The leukaemic cells in de novo PLL are usually CD5 - and patients usually present with massive splenomegaly. In our case, however, the morphology of the leukaemic cells was unlike that seen in PLL. Ultrastructural studies later demonstrated short polar villous projections, confirming a diagnosis of SLVL.

A close relationship has been suggested between HCL and SLVL, and TRAP positivity has been reported in SLVL. ${ }^{1}$ However, absence of CD11c antigen, nodular white pulp involvement of the spleen, and absence of circumferential villous projections on the leukaemic cells excluded a diagnosis of HCL and variant $\mathrm{HCL}$.

Splenic involvement is common in SCCL, and the spleen shows a miliary pattern of involvement on gross examination because of expansion of the white pulp, not unlike that seen in our case. Cytologically, however, SCCL shows a monotonous proliferation of lymphocytes with highly irregular nuclei (cleaved cells). Immunophenotypically, SCCL cells are usually positive for the CD10 antigen. MCL would be difficult to exclude on a purely morphological basis. The cytology of the neoplastic cells in MCL and SLVL is very similar. However, as with SCCL, splenic involvement in MCL is usually evident only when the lymphoma is disseminated and the patient has generalised lymphadenopathy. The peripheral blood counts, although not usually high, can reach $269 \times 10^{9}$ in $\mathrm{MCL}{ }^{6}$ Also, the neoplastic cells in MCL are usually CD5+. Demonstration of translocations involving $11 \mathrm{q} 13$ in MCL and approximately $20 \%$ of SLVL cases $^{7}$ suggests these two disorders may be closely related, and we believe that the morphological features of the neoplastic cells supports this relationship.

We observed marked clumping of lymphoma cells in the peripheral blood smears prepared from EDTA anticoagulated blood. Such a phenomenon has been described in only one previous report, which incidentally described a patient with SLVL. ${ }^{8}$ These authors stated that this finding had never been described before, in either leukaemias or lymphomas involving the peripheral blood. The cause of this clumping remains uncertain but has been attributed to the presence of EDTA.

We believe that the most interesting aspect of this case is the occurrence of SLVL in a patient with family history of a B cell lymphoproliferative disorder. It is conceivable that the patient's brother and father also suffered from SLVL, particularly as we were able to find one previous report describing occurrence of SLVL in two sisters. ${ }^{9}$ However, with the limited material available for study on the relatives, this possibility is speculative. Absence of splenomegaly in the father does not exclude a diagnosis of SLVL. In the study by Melo et $a l^{1}$ only 18 of the 22 patients with SLVL had splenomegaly, and in another study by Oscier et al $^{10}$ only 23 of 31 patients presented with an enlarged spleen. In addition, Bassan et al $^{11}$ have reported a monoclonal $\mathbf{B}$ cell lymphocytosis 
without organomegaly as an early form of SLVL.

In case of the patient's brother, presence of splenomegaly, refractoriness to chemotherapy and a possible transformation to large cell lymphoma would be consistent with a diagnosis of SLVL. Demonstration of CD5 antigen coexpression on B cells is not diagnostic of BCLL. In a recent study of 100 SLVL cases, Matutes et al $^{12}$ found CD 5 expression in $19 \%$ of the cases. Therefore, in the absence of detailed immunophenotypic and ultrastructural studies, we cannot exclude the possibility of SLVL in the patient's relatives.

We conclude that a detailed work up of small B-cell lymphoproliferative disorders can help accurately classify these disorders and these distinctions may have important therapeutic implications. ${ }^{13}$
1 Melo JV, Hegde U, Parreira A, Thompson I, Lampert IA, Catovsky D. Splenic B cell lymphoma with circulating villous lymphocytes: differential diagnosis of B cell leuk- aemias with large spleens. $\mathcal{F}$ Clin Pathol 1987;40:642-51.
2 Neiman RS, Sullivan AL, Jaffe R. Malignant lymphoma simulating leukemic reticuloendotheliosis. A clinico- pathologic study of ten cases. Cancer 1979;43:329-42.
3 Spriano P, Barosi G, Invernizzi R, Ippoliti G, Fortunato A, Rosso R, et al. Splenomegalic immunocytoma with

circulating hairy cells. Report of eight cases and revision of the literature. Haematologica 1986;71:25-33.

4 Conley LC, Misiti J, Laster AJ. Genetic factors predisposing to chronic lymphocytic leukemia and to autoimmune disease. Medicine 1980;59:323-34.

5 Knowles DM, Chadburn A, Inghirami G. Immunophenotypic markers useful in the diagnosis and classification of hematopoietic neoplasms. In: Knowles DM ed. Neoplastic hematopathology. Baltimore: Williams and Wilkins, 1992:73-168.

6 De Oliviera MS, Jaffe ES, Catovsky D. Leukaemic phase of mantle zone (intermediate) lymphoma: its characterisation in 11 cases. $\mathcal{F}$ Clin Pathol 1989;42:962-72.

7 Oscier D, Matutes E, Gardiner A, Glide S, Mould S, Brito-Babapulle V, et al. Cytogenetic studies in splenic lymphoma with villous lymphocytes. Blood 1991;78:113A.

8 Juneja S, Wolf M, McLennan R. Clumping of lymphoma cells in peripheral blood induced by EDTA. $f$ Clin Pathol cells in periphera

9 Ribeiro I, Costa MM, Fernandes BA, Sousa I, Melo A, Parreira A, et al. Splenic lymphoma with villous lymphocytes in two sisters. $\mathcal{F}$ Clin Pathol 1992;45:1111-13.

10 Oscier D, Matutes E, Gardiner A, Glide S, Mould S, Brito-Babapulle V, et al. Cytogenetic studies in splenic lymphoma with villous lymphocytes. Br f Haematol 1993; 85:487-91.

11 Bassan R, Neonato MG, Abbate $M$, Motta $T$, Barbui $T$, Rambaldi A. Monoclonal lymphocytosis with villous lymphocytes: A chronic lymphoproliferative disease of CD11c ${ }^{+}$B-cells. Leukemia 1991;5:799-806.

12 Matutes E, Morilla R, Owusu-Ankomah K, Houlihan A Catovsky D. The immunophenotype of splenic lymphoma with villous lymphocytes and its relevance to the differential diagnosis with other B-cell disorders. Blood 1994 83:1558-62.

13 Mulligan S, Matutes E, Dearden C, Catovsky D. Splenic lymphoma with villous lymphocytes: natural history and response to therapy in 50 cases. Br 7 Haematol 1991;78: 206-9.

\title{
Lipoprotein composition and serum $\mathrm{Lp}(\mathrm{a})$ lipoprotein in hypobetalipoproteinaemia
}

\author{
M Crook, R Swaminathan
}

Department of Clinical Biochemistry, 5th Floor Tower, Guy's Hospital, London SE1 9RT M Crook R Swaminathan

Correspondence to: Dr Martin Crook.

Accepted for publication 26 September 1994

\begin{abstract}
A family with hypobetalipoproteinaemia was studied to examine the $L p(a)$ lipoprotein, lipoprotein cholesterol, and triglyceride composition of the serum lipids. Lp(a) lipoprotein was measured by immunoassay. Serum lipoproteins were separated by ultracentrifugation. Cholesterol and triglycerides were measured using standard enzymatic assays. Serum apolipoprotein $B$ was low and $L p(a)$ undetectable in the index patient and in her father and son. Separation of the lipoproteins by ultracentrifugation showed a low cholesterol content of serum low density lipoprotein in the affected family members and also a low triglyceride content of high density lipoprotein particles in two affected members. It is concluded that serum lipoprotein cholesterol is altered in hypobetalipoproteinaemia, and family
\end{abstract}

members of index cases have undetectable serum Lp(a) lipoprotein concentrations. (f Clin Pathol 1995;48:587-589)

Keywords: Hypobetalipoproteinaemia, Lp(a) lipoprotein, lipoprotein composition.

Hypobetalipoproteinaemia is a rare autosomal dominant condition characterised by low serum cholesterol concentrations. The exact biochemical defect is not known although truncated forms of apolipoprotein B (ApoB) have been described. ${ }^{1}$ Heterozygotes tend to be asymptomatic, whereas homozygous individuals may present with neurological sequelae similar to individuals with abetalipoproteinaemia. $\mathrm{Lp}$ (a) lipoprotein is considered to be a cardiovascular risk factor, yet how it exerts this action is unclear; possibly it acts in part by counteracting the fibrinolytic system. ${ }^{2-4}$ There are few published data upon Lp(a) lipo- 